\title{
Tempo e evidencialidade na língua Kaingang - uma abordagem experimental
}

\author{
Tense and evidentiality in Kaingang - an experimental approach \\ Márcia Nascimento \\ Marcus Maia \\ Leticia Rebollo Couto \\ Universidade Federal do Rio de Janeiro - Rio de Janeiro - Brasil
}

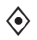

\begin{abstract}
Resumo: Neste artigo reportamos dois experimentos off-line cronométricos investigando as categorias de Tempo e Evidencialidade na língua Kaingang (família Jê, tronco Macro-Jê). No primeiro experimento, identificamos um processo suprassegmental atuante sobre a categoria de Tempo nesta língua. Em verbos finalizados por segmentos consonantais, a prosódia opera como traço distintivo de passado e futuro, tanto em enunciados assertivos, quanto em interrogativos. Através desse experimento e também de análises acústicas, mostramos que a língua Kaingang, conhecida como uma língua acentual, apresenta tom gramatical atuando na categoria de tempo. No segundo experimento, verificamos a compreensão de dois marcadores de evidencialidade que se opõem quanto à fonte da informação, mỹr para informação visual e je para informação reportada. Objetivou-se testar a interpretação semântica que os falantes atribuem a essas partículas. Através de um subgrupo de sentenças, testamos, também, a partícula de modalidade $v \tilde{a}$, que indica frustrativo. Em ambos os experimentos, os resultados confirmaram as nossas hipóteses.
\end{abstract}

Palavras-chave: Tempo; Evidencialidade; Kaingang; Psicolinguística experimental

\begin{abstract}
In this article we report two chronometric off-line experiments investigating the categories of tense and evidentiality in the Kaingang language (Je family, Amerindian, MacroJe stock). In the first experiment, we found an active suprassegmental process acting in the Tense category in this language. In verbs ending by consonantal segments, prosody operates as a phonemic feature, distinguishing past and future, both in assertive statements, and in questions. Based on this experiment we developed acoustic analyses which show that the Kaingang language, known as an accentual language, displays a system of grammatical tones acting in the category of Tense. In the second experiment, we studied the comprehension of two evidentiality markers which differ as to the source of the information they identify: $m \tilde{y} r$ encodes visual information and je indicates reported information. This study aimed to test the semantic interpretation that users assign to these particles. Through a subset of sentences, we tested also the modality particle $v \tilde{a}$, which indicates frustrative mode. In both experiments, the results confirmed our hypotheses.
\end{abstract}

Keywords: Tense; Evidentiality; Experimental Psycholinguistics; Kaingang language

\section{Introdução}

O objetivo do presente artigo é o de apresentar dois estudos psicolinguísticos investigando duas categorias gramaticais da língua Kaingang - Tempo e Evidencialidade - atestando como a Psicolinguistica Experimental, até aqui ainda pouco utilizada na pesquisa sobre línguas indígenas, pode, de fato, ser uma ferramenta relevante para estabelecer dados mais precisos e explicações melhor fundamentadas sobre fenômenos gramaticais em línguas indígenas. A categoria gramatical do Tempo será abordada através da análise de fenômeno raro nas línguas, na interface entre a morfologia e a prosódia. A categoria da Evidencialidade foca em três partículas que modalizam a compreensão da frase em Kaingang, constituindo, portanto, uma questão semântica. 
A lingua Kaingang é hoje uma das línguas indígenas brasileiras com maior número de falantes. É falada entre uma população de aproximadamente 30 mil pessoas, distribuídas em 32 terras indígenas, nos três estados do sul do Brasil (Paraná, Santa Catarina, Rio Grande do Sul) e também em região do estado de São Paulo. Em decorrência desta ampla distribuição geográfica, a lingua apresenta cinco variantes dialetais distintas. De acordo com Rodrigues (1986), dentre as línguas da família Jê, o Kaingang é o ramo mais diferenciado, com maior proximidade ao Xokleng, com que constitui o ramo Jê meridional.

Como demonstrado em Nascimento (2013), a partir da intuição de falante nativa da própria autora sobre essas estruturas gramaticais da língua Kaingang, procedeu-se à elaboração dos experimentos a fim de obter uma aferição empiricamente precisa desses fenômenos. Trata-se de dois experimentos de natureza off-line formulados no âmbito do Laboratório de Psicolinguística ExperimentalLAPEX da UFRJ, aplicados a falantes nativos de Kaingang residentes na Terra Indígena Nonoai, localizada ao norte do Rio Grande do Sul. No primeiro experimento, testamos a compreensão de um processo suprassegmental, que denominamos de flexão prosódica, que atua sobre um grupo específico de verbos como traço distintivo de tempo passado e de tempo futuro, tanto em enunciados assertivos quanto em interrogativos. $\mathrm{O}$ teste perceptual foi aplicado a falantes nativos da língua Kaingang, a fim de verificar a hipótese de que a flexão melódica estaria atuando como traço de flexão gramatical para distinguir noções temporais na língua Kaingang, opondo passado e futuro em verbos do tipo "não-flexionais", os quais terminam em segmentos consonantais e não se flexionam morfologicamente. Trata-se de uma função da inflexão da frequência fundamental F0 ou da altura melódica, para expressar passado e futuro, que não corresponde exatamente à descrição do tom (nível lexical), nem da entoação (nível do enunciado), uma vez que a oposição se dá no nível da morfologia verbal, conforme proposto em nossa análise. A partir dos resultados desse experimento, realizamos análises acústicas, para estabelecer os tipos de contorno da Frequência fundamental F0 e da altura melódica que distinguem as noções temporais de passado e futuro. No segundo experimento, nosso objetivo foi o de investigar de modo mais preciso a interpretação que os falantes nativos atribuem a algumas das diferentes partículas evidenciais na língua. Foram testados os dois evidenciais que se opõe quanto à fonte da informação, a saber, $m \tilde{r} r$ para informação visual/experienciada e je para informação reportada. E, ainda, através de um subgrupo de sentenças testamos, também, a compreensão da partícula de modalidade $v \tilde{a}$, que indica uma consequência frustrada da ação do verbo principal.
A partícula mỹr indica informação visual do falante, sendo, portanto, o próprio falante, a fonte da informação. Por outro lado, a partícula je indica informação reportada, tratando-se, portanto, de uma fonte externa ao falante. Dessa forma, essas partículas estariam codificando informações que podem ser traduzidas como: 'eu vi que isso aconteceu' e 'contaram-me que isso aconteceu', respectivamente.

A utilização de procedimentos experimentais para capturar os processos de compreensão de estruturas contendo partículas de evidencialidade pode nos fornecer pistas importantes em relação aos processos mentais ativados por essas estruturas gramaticais, sendo, por isso, diretamente relevante para o objetivo central das teorias de processamento de frases, que é o de identificar os procedimentos psicologicamente reais que colocamos em jogo ao produzir e compreender palavras e frases.

Utilizando técnicas aptas a captar e mensurar, em milésimo de segundos, diferentes processos cognitivos, a Psicolinguística Experimental pode, portanto, contribuir na busca de aferições mais precisas das nuances de significados que as partículas de evidencialidade codificam nas línguas. Sobretudo, pode também nos fornecer pistas que auxiliem para identificar as distinções das categorias TAME, visto que estas costumam ser categorias intimamente ligadas entre si, impondo, portanto, um desafio para a sua caracterização. Sabe-se que, em muitas línguas, a evidencialidade, por exemplo, é codificada por morfemas portmanteau, que codificam também tempo e aspecto (cf. DE HAAN, 2012).

Antes da apresentação dos experimentos, faremos uma breve discussão sobre como as categorias de Tempo e Evidencialidade se estruturam na língua Kaingang.

\section{A categoria de tempo e a flexão prosódica na língua Kaingang}

A língua Kaingang, conhecida na literatura como uma língua acentual, apresenta um caso interessante de flexão prosódica relacionada ao sistema de marcação de tempo. Além de unidades lexicais, partículas e morfemas gramaticais, essa língua apresenta tom gramatical atuando sobre a categoria de tempo. Segundo Nascimento (2013), na língua Kaingang, os verbos se organizam em dois grupos principais quanto à flexão de tempo. Verbos finalizados em segmentos vocálicos realizam a flexão morfológica de tempo, enquanto que verbos finalizados em segmentos consonantais não admitem flexão morfológica e sim flexão prosódica ou, mais especificamente, a inflexão no contorno da frequência fundamental F0 para expressar passado e futuro, tanto em enunciados assertivos, quanto em interrogativos, conforme mostrado na Tabela 1, a seguir. 
Tabela 1. Flexão verbal de tempo em Kaingang ${ }^{1}$

\begin{tabular}{ll|}
\hline \multicolumn{1}{c}{$\begin{array}{c}\text { Verbos finalizados por } \\
\text { segmentos vocálicos }\end{array}$} & $\begin{array}{c}\text { Verbos finalizados por } \\
\text { segmentos consonantais }\end{array}$ \\
\hline Morfema de futuro $-j$ & \\
I $\quad$ Alternância vocálica para passado & \\
II $\quad$ Morfema de passado $-g$ & \\
& \\
& Morfemas tonais: \\
& H - futuro \\
& $L$ - passado \\
\hline
\end{tabular}

Conforme a Tabela 1, todos os verbos do primeiro grupo, os finalizados por segmentos vocálicos, independentemente do subgrupo, realizam flexão de futuro através do morfema $-j$, como demonstrado no exemplo (1) em que a forma básica do verbo 'banhar' é vẽnhkype. Nesse grupo há ainda o subgrupo I que realiza flexão de passado através da alternância vocálica, como se pode ver em (2), em que a forma básica do verbo 'comer' é $k o$. O subgrupo II realiza flexão, também de passado, através do morfema $-g$, como se pode observar em (3) em que o forma básica do verbo 'correr' é vẽnhva. Observem-se os respectivos exemplos.

(1) Gĩr tĩ vẽnhkypej.

criança NUC REF.lavar.FUT

'A criança vai tomar banho.'

(2) Gĩr tỹ ẽmĩ kó.

criança NUC pão comer.PASS

'A criança comeu o bolo.'

(3) Gĩr ne vẽnhvãg.

criança MIR correr.PASS

'A criança correu.'

O grupo de verbos que realizam flexão de passado através do morfema -g, é um grupo muito restrito e o que parece motivar essa flexão é a partícula de miratividade ne localizada após o sujeito. Portanto, parece haver uma interação entre essas partículas pós-sujeito e os tipos de verbos. E ainda, observa-se o apagamento das marcas de modo e aspecto que ocorrem no final das sentenças, após o verbo. São questões que pontuamos para futuros estudos.

A única característica realmente sistemática observada, que parece motivar esses tipos de flexão nos verbos em Kaingang, é a estrutura fonológica.

Já para os verbos do segundo grupo, os finalizados por segmentos consonantais, a flexão de tempo é percebida pela altura melodica, alto $(\mathrm{H})$ para futuro e baixo $(\mathrm{L})$ para passado, em verbos como 'dormir' nũr e 'plantar' krẽn, como será mostrado com mais detalhe na seção 3, através das análises dos experimentos e da análise acústica.

\footnotetext{
Tabela reproduzida de Nascimento (2013, p.46), com ligeiras modificações.
}

Todos os verbos foram analisados em sentenças do tipo SOV, que é a ordem padrão básica para o Kaingang. Por essa razão, a análise acústica foi importante para mapear a estrutura prosódica e verificar se a flexão prosódica estaria atuando no nível do enunciado, ou exatamente sobre os verbos.

\section{Evidencialidade na língua Kaingang}

A definição da categoria de Evidencialidade nas línguas ainda é uma questão não consensual entre os pesquisadores dessa área. Muitas vezes assume-se que a evidencialidade é um tipo de modalidade epistêmica, ou até mesmo uma subcategoria. Outros autores como Aikhenvald $(2003,2004)$ estabelecem uma especificação entre essas categorias, assumindo que a Evidencialidade constitui uma categoria gramatical por si própria, e que esta se refere à fonte da informação transmitida.

Assim, a evidencialidade, de modo geral, caracteriza-se por ser uma marca relacionada à fonte de informação do falante, enquanto que a modalidade epistêmica está relacionada ao conhecimento/julgamento do falante com respeito ao grau de confiança na informação.

Segundo Nascimento (2013) o sistema de marcação da evidencialidade na língua Kaingang se organiza em dois grandes grupos que se opõem quanto à fonte de informação, a saber, informações que vêm de outros e informações onde o próprio falante é a fonte da informação, e são organizados basicamente a partir da oposição "Primeira mão" e "Ouvir dizer (de outros)"como distinção primária. Esse sistema é composto fundamentalmente por dez marcadores que codificam diferentes nuances de evidencialidade, representados em diferentes categorias: relatada, visual, não-visual, Inferência e suposição. E, como categoria relacionada à Evidencialidade, observou-se ainda a ocorrência da partícula ne que indica miratividade, ou seja, indica a admiração ou a surpresa do próprio falante em relação à informação que esta sendo transmitida. Assume-se, portanto, que na língua Kaingang há elementos ou partículas próprias de evidencialidade, o que quer dizer que a função primária desses termos é a marcação da evidencialidade, enquanto que outras partículas possuem outra função primária, mas exercem também uma estratégia de evidencialidade.

Tabela 2. Categorias de Evidencialidade em Kaingang.

\begin{tabular}{ll}
\hline Primeira Mão & mỹr - Visual \\
& vẽnhver - Visual Fraco \\
& mẽm - Não-Visual (Auditivo) \\
& $n$ e - Mirativo \\
& ja - Inferencia (constatações). \\
& tũ - Negação (contrafactual/contra-expectativa) \\
& $\boldsymbol{h e ̃ n}-$ Suposição \\
\hline Ouvir Dizer & je - Reportativo \\
& jetóg - Reportativo (modalizador da credibilidade) \\
& nẽji - Reportativo (narrativa Gufã)
\end{tabular}


Para o estudo experimental, que será detalhado na seção 3.2, testamos a compreensão dos principais marcadores que se opõem quanto à fonte de informação. Neste sentido, temos a partícula $m \tilde{r} r$ indicando evidência visual e a partícula je que indica evidência reportada. A partícula mỹr ocupa a posição final da sentença, logo após o verbo, sendo que a variante dialetal falada em Nonoai, dispensa as marcas de modo e aspecto, como exemplificado em (4).

(4) Mỹrinh fi tỹ kafej krãn mỹr. Maria 3SG.F NUC flor plantar VIS 'Maria plantou uma flor (eu vi que isso aconteceu).'

A partícula $m \tilde{r} r$ é um evidencial relacionado a contextos perfectivos apenas. No entanto, verificou-se que em outras variantes pode co-ocorrer com as marcas de aspecto em um tipo especifico de narrativa.

Quanto à partícula je, exemplificada em (5), esse marcador evidencial é pós-sujeito, podendo ocorrer tanto em contextos perfectivos, quanto em imperfectivos, permitindo a ocorrência de outros marcadores de aspecto e modo no final da sentença.

(5) Mỹrinh $f i$ je tỹ kafej krãn. Maria 3SG.F REP NUC flor plantar 'Maria plantou uma flor (me contaram que isso aconteceu).'

Neste mesmo experimento, testamos, também, a compreensão da partícula $v \tilde{a}(\sim v \tilde{e})$, que é muito recorrente na comunicação cotidiana. Essa partícula de modalidade indica uma consequência frustrada da ação do verbo, ou mesmo um efeito contrario, como exemplificado a seguir.

(6) Is ỹ vẽnhkagta kron mỹr hori vã. 1SG.NUC remédio tomar VIS já FRUST 'Eu já tomei o remédio (mas continuo doente)'.

\section{Experimentos}

\subsection{Teste de compatibilidade da flexão prosódica}

O experimento baseou-se no paradigma de audição automonitorada de sentença interrogativa, seguida de sentença resposta, formando condições simétricas e assimétricas quanto à noção temporal de passado e de futuro, consistindo a tarefa experimental em avaliar a compatibilidade entre as duas sentenças, registrando-se, além dos índices de julgamento, também os tempos médios de decisão.

Foram elaboradas 32 sentenças interrogativas, metade com a prosódia indicando tempo passado e a outra metade indicando tempo futuro. Da mesma forma, elaboramos 32 frases respostas, metade indicando passado e a outra metade indicando futuro, como exemplificado no quadro a seguir.

Quadro 1. Exemplo de materiais

\begin{tabular}{|c|c|c|c|c|c|c|}
\hline$(\mathrm{PP})$ & $\begin{array}{ll}\text { Mỹrinh fi } \\
\text { Maria FEM } \\
\text { 'Quantos cestos }\end{array}$ & $\begin{array}{l}m \tilde{y} \\
\text { INT } \\
\text { Maria f }\end{array}$ & $\begin{array}{l}\text { kãj } \\
\text { cest } \\
\text { fez' }\end{array}$ & & $\begin{array}{l}\text { hẽre } \\
\text { uantos }\end{array}$ & $\begin{array}{l}\text { han? } \\
\text { fazer }\end{array}$ \\
\hline$(\mathrm{PF})$ & $\begin{array}{l}\text { Mỹrinh fi } \\
\text { Maria FEM } \\
\text { 'Quantos cestos }\end{array}$ & $\begin{array}{l}m \tilde{y} \\
\text { INT } \\
\text { Maria }\end{array}$ & $\begin{array}{c}\text { kãj } \\
\text { cest } \\
\text { vai faz }\end{array}$ & $\begin{array}{r}t \bar{y} \\
\mathrm{q} \\
\mathrm{er} ?\end{array}$ & $\begin{array}{l}\text { hare } \\
\text { uantos }\end{array}$ & $\begin{array}{l}\text { han'? } \\
\text { fazer }\end{array}$ \\
\hline (RP) & $\begin{array}{l}\text { Ũntegtũ han } \\
\text { três fazer } \\
\text { 'Ela fez três' }\end{array}$ & $\begin{array}{l}\text { fi } \\
\text { 3SG.F }\end{array}$ & FEM & tóg. & & \\
\hline (RF) & $\begin{array}{l}\text { Unntegtũ han } \\
\text { três fazer } \\
\text { 'Ela vai fazer trê }\end{array}$ & $\begin{array}{l}\text { jé } \\
\text { FUT }\end{array}$ & $\begin{array}{l}\text { fi } \\
3 S G\end{array}$ & & $\begin{array}{l}\text { tóg. } \\
\text { MS }\end{array}$ & \\
\hline
\end{tabular}

As sentenças foram distribuídas em um desenho do tipo quadrado latino, dividindo-se os materiais em 4 versões, de modo que os sujeitos do experimento fossem expostos a todas as condições, mas não às diferentes versões das mesmas frases, que são comparadas "entre sujeitos". Cada versão foi aplicada a 8 sujeitos.

\section{Variáveis independentes:}

Tivemos como variáveis independentes, os fatores flexão prosódica (passado e futuro), simetria (simétrico e assimétrico) e aceitabilidade (sim e não), resultando em um design $2 \times 2 \times 2$.

\section{Variáveis dependentes:}

As variáveis dependentes foram duas, a saber, os índices de respostas e os tempos médios de julgamento.

\section{Hipótese:}

Trabalhamos com a hipótese de que a flexão prosódica estaria atuando como traço distintivo de passado e futuro em verbos que não flexionam morfologicamente.

\section{Participantes:}

Participaram do experimento 32 falantes de Kaingang, sendo 22 do sexo masculino e 10 do sexo feminino com idades entre 11 e 56 anos.

\section{Procedimentos:}

Os participantes foram instruídos a ouvir a sentença interrogativa seguida da resposta, devendo então, julgar rapidamente se as sentenças de interrogação e a resposta eram compatíveis ou não (simétricas ou assimétricas), apertando a tecla verde ou a tecla vermelha respectivamente, de acordo com sua avaliação

\section{Resultados:}

Como veremos, confirmando nossas hipóteses, os resultados, de fato, mostraram que as condições simétricas tanto para futuro, quanto para passado, obtiveram o maior 
Tabela 3. Resultados dos índices e tempos de decisão

\begin{tabular}{|c|c|c|c|c|c|c|c|c|}
\hline \multirow{2}{*}{ Col. stats } & PF RF s & PF RF n & PF RP s & PF RP n & PP RP s & PP RP n & PP RF s & PP RF n \\
\hline & $\mathbf{Y}$ & $\mathbf{Y}$ & $\mathbf{Y}$ & $\mathbf{Y}$ & $\mathbf{Y}$ & $\mathbf{Y}$ & $\mathbf{Y}$ & $\mathbf{Y}$ \\
\hline Number of values & 109 & 19 & 52 & 76 & 109 & 19 & 55 & 73 \\
\hline Mean & 2288 & 3130 & 3347 & 2151 & 3040 & 4533 & 5293 & 4450 \\
\hline Std. Deviation & 3289 & 1693 & 2373 & 2889 & 4708 & 4710 & 8194 & 6690 \\
\hline
\end{tabular}

índice de aceitabilidade, sendo elas também mais rápidas de processar, quando comparadas com as condições assimétricas, como se pode verificar na Tabela 3.

\section{Condições simétricas e assimétricas para futuro -} variável categórica: índices de aceitabilidade. A condição simétrica de futuro (PFRF - Enunciado Interrogativo no Futuro e Resposta no Futuro) obteve 109 observações positivas, enquanto que a condição assimétrica de futuro (PFRP - enunciado Interrogativo no Futuro e Resposta no Passado) obteve apenas 52 observações positivas, diferença que produz resultados altamente significativos no test Chi quadrado: $\mathrm{X}^{2}=40,4, \mathrm{p}=0,0001^{* * *}$. Ou seja, a probabilidade dessa distribuição ter sido randômica é ínfima, o que garante que a preferência pela decisão simétrica deveu-se, de fato, à variável prosódica manipulada no experimento.

Para a variável contínua, tempos médios de decisão, a condição simétrica de futuro (PFRF) obteve 109 observações positivas respondidas em um tempo médio de $2288 \mathrm{~ms}$, enquanto que a condição assimétrica de futuro (PFRP) obteve apenas 52 observações positivas, que foram respondidas em um tempo médio de $3347 \mathrm{~ms}$. Esta diferença de tempos médios de resposta produz resultados significativos no teste- $\mathrm{T}$ : $\mathrm{t}(159)=2,08, \mathrm{p}=0,04 *$. Assim, observe-se que dizer sim para a condição simétrica foi significativamente mais rápido do que dizer sim para a condição assimétrica, conforme predito em nossas hipóteses.

\section{Condições simétricas e assimétricas para passado} - variável categórica: índices de aceitabilidade. A condição simétrica de passado (PPRP - Enunciado Interrogativo no Passado e Resposta do Passado) obteve 109 observações positivas, enquanto que a condição assimétrica de passado (PPRF - Enunciado Interrogativo no Passado e Resposta no Futuro) obteve apenas 55 observações positivas, diferença que produz resultados altamente significativos no teste Chi quadrado: $\chi^{2}=35,6, p=0,0001 * * *$. Ou seja, a probabilidade dessa distribuição ter sido randômica é ínfima, o que garante que a preferência pela decisão simétrica no passado deveu-se, de fato, à variável prosódica manipulada no experimento.

$\mathrm{Na}$ variável contínua: tempos médios de decisão, a condição simétrica de passado (PPRP) obteve 109 observações positivas respondidas em um tempo médio de $3040 \mathrm{~ms}$, enquanto que a condição assimétrica de passado (PPRF) obteve apenas 55 observações positivas, que foram respondidas em um tempo médio de 5293 ms. Esta diferença de tempos médios de resposta produz resultados significativos no teste-T: $\mathrm{t}(162)=2,235$, $\mathrm{P}=0,0268^{*}$. Assim, observe-se que dizer sim para a condição simétrica no passado foi significativamente mais rápido do que dizer sim para a condição assimétrica, conforme predito em hipóteses. Resultados que também podem ser observados nos Gráficos 1 e 2 .

Gráfico 1. Índices de decisão para as condições simétricas e assimétricas

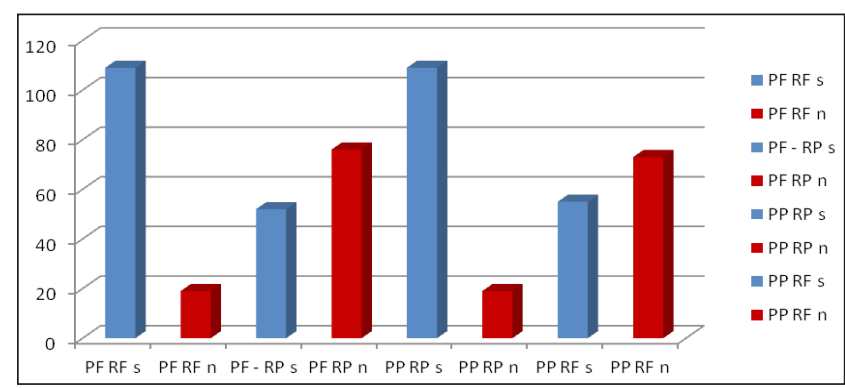

Gráfico 2. Tempos médios de decisão para as condições simétricas e assimétricas

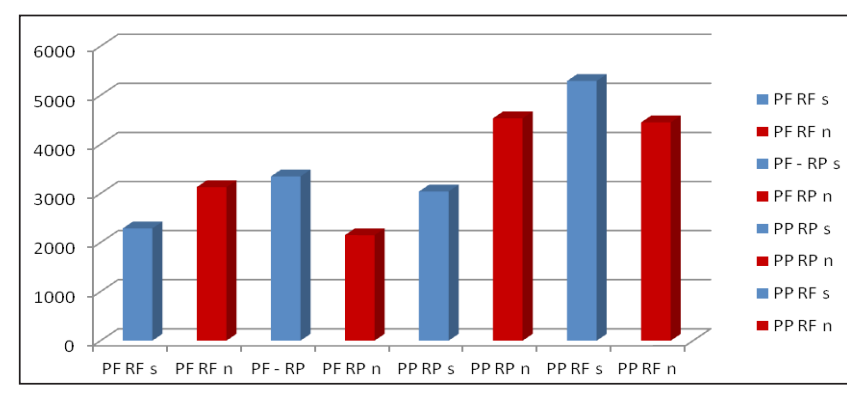

\subsubsection{Analise acústica 1}

Nosso corpus consistiu-se de 64 enunciados, divididos em 32 interrogativos e 32 assertivos. Com base no modelo métrico autossegmental de Pierrehumbert (1980), fez-se a análise acústica no programa Praat. Observou-se que o contorno ascendente $\left(\mathrm{H}^{*} \mathrm{H} \%\right)$ e o contorno descendente $(\mathrm{L} * \mathrm{~L} \%)$ de $\mathrm{F} 0$ marca a oposição 
contrastante entre o acento nuclear passado e o acento nuclear futuro, tanto em enunciados assertivos quanto interrogativos como mostrado nas Figura 1 e 2.

Observou-se também que o contraste de modalidade assertiva e interrogativa no futuro se dá pelo tom das partículas: alto $\left(\mathrm{H}^{*}\right)$ para a partícula assertiva de sujeito ' $t \tilde{y}$ '; ascendente $\left(\mathrm{L}+\mathrm{H}^{*}\right)$ para a partícula interrogativa ' $m \tilde{y}$ '.

Nas Figuras 3 e 4 temos o mesmo par de enunciados, um assertivo e outro interrogativo, mas desta vez, com o contorno de F0 ascendente no acento nuclear marcando traço de futuro.

Com esses resultados demonstra-se que o contorno ascendente de $\mathrm{F} 0$ (marcado com o acento nuclear $\mathrm{H}^{*} \mathrm{H} \%$ ), é $100 \%$ recorrente em todo o corpus observado, 32 casos de futuro, seja em enunciados interrogativos ou assertivos. Enquanto que, o contorno descendente de F0 (marcado com o acento nuclear $\mathrm{L} * \mathrm{~L} \%$ ), também é $100 \%$ recorrente em todos os 32 casos de passado, seja em enunciados interrogativos ou assertivos. Observou-se, também, que a modalidade da frase se distingue pelo tom das partículas: alto $\left(\mathrm{H}^{*}\right)$ para a partícula assertiva de sujeito $t \tilde{y}$; ascendente $\left(\mathrm{L}+\mathrm{H}^{*}\right)$ para a partícula interrogativa ' $m \tilde{y}$ '.

\subsubsection{Análise acústica 2}

A fim de obter uma análise mais precisa da atuação da flexão prosódica, julgou-se necessário fazer uma segunda análise. O corpus analisado consistiu-se de 32 enunciados gravados por um falante nativo de Kaingang de 33 anos de idade que reside na Terra indígena Nonoai, e foram assim divididos: 16 enunciados assertivos, metade desses enunciados apresentando ao final da sentença o advérbio rêkétá 'ontem' e a outra metade com o advérbio vajkỹ 'amanhã', também no final da sentença. Da mesma forma, elaboramos a outra parte de 16 enunciados interrogativos utilizando os mesmo advérbios de tempo 'ontem' e 'amanhã' no final dos enunciados.

Para a elicitação dos dados para o teste, o conjunto de sentenças foi previamente elaborado em Kaingang pela autora que é falante nativa de Kaingang e, em seguida aplicou-se um questionário em português das mesmas sentenças a outros cinco falantes com idade entre 17 a 60 anos solicitando que eles traduzissem as sentenças para o Kaingang. Os dados foram comparados e depois gravados.

$\mathrm{O}$ acréscimo dos advérbios ao final das sentenças nos permite tirar o verbo da margem sem alterar a estrutura da sentença, possibilitando-nos assim, identificar a atuação exata da flexão prosódica. Trabalhamos com a hipótese de que a inflexão de F0 que marca a distinção de passado e futuro estaria acontecendo no nível do verbo, tratando-se, portanto, de um tom verbal, uma vez que essa classe de verbos se distingue de outros por sua morfologia não flexional.

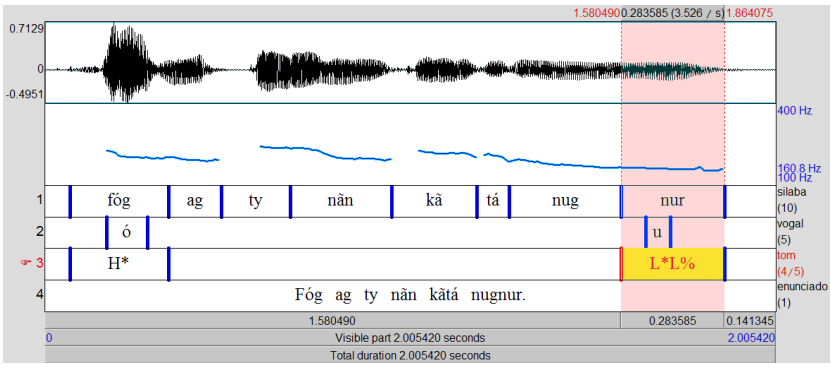

Figura 1. Contorno de F0 em assertiva no passado

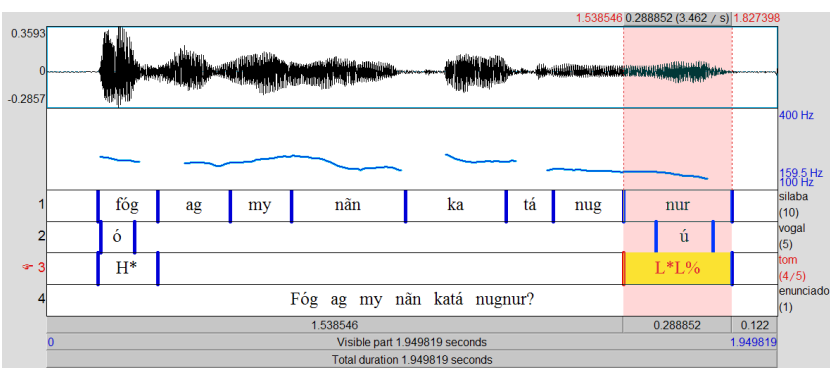

Figura 2. Contorno de F0 em interrogativa no passado

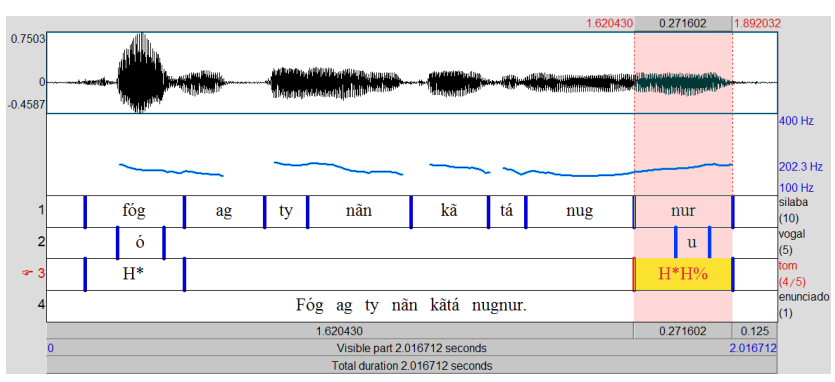

Figura 3. Contorno de F0 em assertiva no futuro

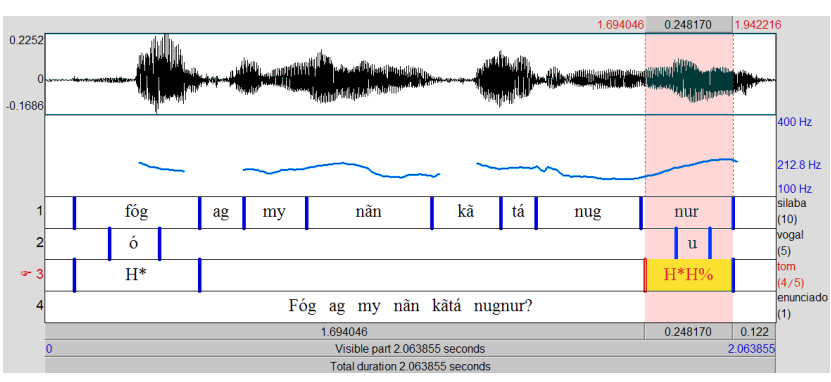

Figura 4. Contorno de F0 em interrogativa no futuro

Analisando a configuração melódica dos verbos nesses enunciados observamos que contornos ascendentes e descendentes continuam acontecendo e marcando essa distinção temporal de passado e futuro em Kaingang, conforme já previsto em nossa hipótese. $\mathrm{O}$ que pode ser observado na figura abaixo, no gráfico de normalização temporal. 


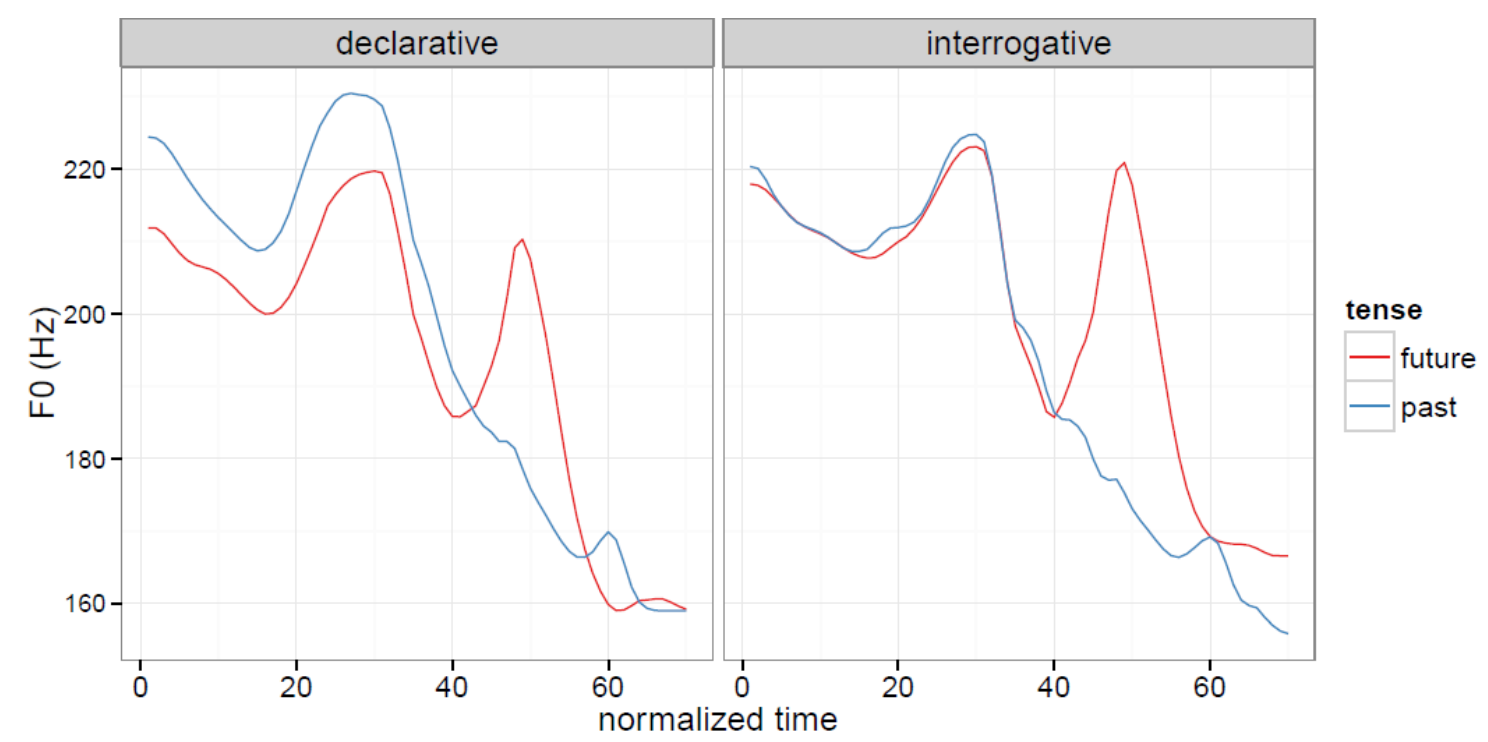

Figura 5. Normalização temporal²

\section{Discussão:}

Nossos dados apontam que essa flexão prosódica estaria mais restrita ao verbo. Temos, portanto, a ocorrência de Tom verbal na língua Kaingang, o que segundo Gussenhoven (em conversa informal durante IV colóquio de prosódia em 2013) se trata de morfemas tonais. Semelhante ao que ocorre na língua Chechena, bem com a língua Xitshwa onde o tom exerce função gramatical, distinguindo tempos e aspectos (Zeferino Maguiuane Ugembe, 2011).

Conforme Hyman (2006), em termos de estrutura prosódica da palavra, pode-se dizer que basicamente há dois fenômenos envolvidos, stress (acento) e tone, e uma vez que nenhum é obrigatório, há quatro possibilidades para uma dada língua: 1 - tone \& stress; 2 - tone \& no stress; 3 - no tone \& stress; 4 - no tone \& no stress.

Dessa forma, a língua Kaingang parece apresentar-se como a combinação em 1 , sendo uma língua basicamente acentual, mas com subsistemas tonal atuando em áreas bem específicas da gramática, como é o caso da flexão de verbo.

\subsection{Experimento de compreensão de evidenciais}

O experimento baseou-se no paradigma de audição automonitorada com avaliação de compatibilidade dos seguintes tipos de sentenças: i) sentenças com os evidenciais visual e reportativo, seguidas de sentenças complementos; e ii) sentenças com frustrativo e não-

\footnotetext{
2 Nossos agradecimentos ao Pablo Arantes pela sua contribuição na discussão dos dados e elaboração do gráfico de normalização.
}

frustrativo, também seguidas de sentenças complementos. Formaram-se, desta maneira, condições simétricas e assimétricas, consistindo a tarefa experimental em avaliar a compatibilidade entre as sentenças e seus complementos. Registraram-se, além dos índices de julgamento, também os tempos médios de decisão. As sentenças foram distribuídas em um desenho do tipo quadrado latino, dividindo-se os materiais em 4 versões, de modo que os sujeitos do experimento fossem expostos a todas as condições, mas não às diferentes versões das mesmas frases, que são comparadas "entre sujeitos". Cada versão foi aplicada a 8 sujeitos, totalizando 32 participantes, todos falantes nativos de Kaingang.

A previsão era de que as condições simétricas teriam o maior índice de aceitabilidade, bem como o tempo de decisão mais rápido do que nas condições assimétricas.

\section{Hipótese:}

As hipóteses testadas foram as seguintes: i) Uma sentença com a partícula $m \tilde{r} r$ que indica informação visual só aceita como complemento a sentença 'eu vi que isso aconteceu'. Da mesma forma, uma sentença com a partícula je que indica informação reportada só aceita como complemento a sentença 'contaram-me que isso aconteceu'; ii) Em relação à partícula vã que indica frustrativo, uma sentença com esse marcador só aceita como complemento uma sentença como o marcador adversativo hãra, já que se trata de uma consequência frustrada.

\section{Variáveis independentes:}

As variáveis independentes foram: O tipo de evidencial (visual, reportativo, frustrativo, não frustrativo), 
a simetria (simétrico e não simétrico) e a aceitabilidade ( $\operatorname{sim}$ e não). Obtivemos, portanto, um design do tipo $4 \times 2 \times 2$, gerando 16 condições experimentais, distribuídas em quadrado latino com 4 versões.

\section{Variáveis dependentes:}

Tempos médios de julgamento e índices de resposta.

\section{Método}

\section{Material e procedimentos}

Para as condições simétricas de evidenciais os estímulos auditivos se davam da seguinte maneira: Uma sentença com o evidencial visual mỹr (EV) tendo como complemento a sentença "eu vi que isso aconteceu" (CV), formando a condição simétrica (EV-CV) para o tipo de evidencia visual. Da mesma forma, uma sentença com o evidencial reportativo je tendo como complemento a sentença "me contaram que isso aconteceu", formando a condição simétrica (ER-CR) para o tipo de evidencia reportada.

Para as condições assimétricas, apresentava-se uma sentença com evidencial visual seguida do complemento com reportativo, formando a condição assimétrica (EV-CR) para a evidencia visual. Da mesma forma, apresentava-se uma sentença com evidencial reportativo seguida do complemento com evidencial visual, formando a condição assimétrica (ER-EV) para evidencia reportada. Observe-se os materiais exemplificados no Quadro 2.

Quadro 2. Exemplo de materiais testados com evidenciais

\begin{tabular}{|c|c|c|c|}
\hline EV & $\begin{array}{lll}\text { Nẽnẽ } & t \tilde{y} & \text { pénky } \\
\text { criança } & \text { NUCL } & \text { prato } \\
\text { 'a criança quebrou o prato }\end{array}$ & $\begin{array}{l}\text { gãm } \\
\text { quebrar }\end{array}$ & $\begin{array}{l}m \tilde{y} \text {. } \\
\text { VIS }\end{array}$ \\
\hline ER & $\begin{array}{lll}\text { Nẽnẽ } & j e & t \tilde{y} \\
\text { criança } & \text { REP } & \text { NUCL } \\
\text { 'a criança quebrou o prato }\end{array}$ & $\begin{array}{l}\text { pénky } \\
\text { prato }\end{array}$ & $\begin{array}{l}\text { gãm. } \\
\text { quebrar }\end{array}$ \\
\hline CV & $\begin{array}{lll}\text { Vég } & m \tilde{r} r & \text { inh. } \\
\text { ver.PASS } & \text { VIS } & 1 \text { 1SG } \\
\text { 'eu vi' } & & \end{array}$ & & \\
\hline CR & $\begin{array}{l}\text { Inh mỹ tó } \\
\text { 1SG POSP contar } \\
\text { 'elas me contaram' }\end{array}$ & $\begin{array}{l}m \tilde{y} r \\
\text { VIS }\end{array}$ & \\
\hline
\end{tabular}

Para testar a compreensão da partícula de modalidade $v \tilde{a}$, apresentava-se uma sentença com a partícula de frustrativo (DF) seguida de complemento marcada pela partícula hãra - traduzida por 'mas' (CF), formando assim a condição simétrica (DF-CF) para o frustrativo. Da mesma forma, para a condição simétrica de nãofrustrativo (DN), apresentava-se a uma sentença sem a partícula de frustrativo seguida do complemento marcada pela partícula $k \tilde{y}$ - traduzida por 'então' $(\mathrm{CN})$, formando assim a condição (DN-CN).
Para as condições assimétricas, apresentava-se uma sentença com a partícula de frustrativo (DF) seguida de complemento marcada pela partícula $k \tilde{y}$ - traduzida por 'então' $(\mathrm{CN})$, formando assim a condição assimétrica (DF-CN) para frustrativo. Da mesma forma, para a condição assimétrica de não frustrativo (DN-CF), apresentava-se uma sentença sem a partícula de frustrativo (DN) seguida do complemento marcada pela partícula hãra - traduzida por 'mas' (CF).

Quadro 3. Exemplo de materiais testados com frustrativo

\begin{tabular}{|c|c|c|c|c|c|c|c|}
\hline DF & $\begin{array}{l}\text { Mĩnká } \\
\text { Mĩnká } \\
\text { 'Mĩnká to }\end{array}$ & $\begin{array}{l}\text { fi } \\
\text { 3SG.F } \\
\text { mou o r }\end{array}$ & $\begin{array}{l}t \tilde{y} \\
\text { NUC } \\
\text { emédio' }\end{array}$ & $\begin{array}{l}\text { vẽnhkagta } \\
\text { remédio }\end{array}$ & $\begin{array}{l}\text { kron } \\
\text { tomar }\end{array}$ & $\begin{array}{l}m \tilde{y} r \\
\text { VIS }\end{array}$ & $\begin{array}{l}\text { vã. } \\
\text { FRUST }\end{array}$ \\
\hline DN & $\begin{array}{l}\text { Mĩnká } \\
\text { Mĩnká } \\
\text { 'Mĩnká to }\end{array}$ & $\begin{array}{l}\text { fi } \\
\text { 3SG.F } \\
\text { mou o r }\end{array}$ & $\begin{array}{l}\text { tỹ } \\
\text { NUC } \\
\text { emédio' }\end{array}$ & $\begin{array}{l}\text { vẽnhkagta } \\
\text { remédio }\end{array}$ & $\begin{array}{l}\text { kron } \\
\text { tomar }\end{array}$ & $\begin{array}{l}\text { mỹr. } \\
\text { VIS }\end{array}$ & \\
\hline CF & $\begin{array}{l}\text { Hãra } \\
\text { mas } \\
\text { 'Mas ela }\end{array}$ & $\begin{array}{l}\text { fi } \\
\text { 3SG.F } \\
\text { não mel }\end{array}$ & $\begin{array}{l}\text { pi } \\
\text { NEG } \\
\text { horou' }\end{array}$ & $\begin{array}{l}\text { gĩnh } \\
\text { melhorar }\end{array}$ & $\begin{array}{l}\text { ke } \\
\text { fazer }\end{array}$ & $\begin{array}{l}\text { mũ. } \\
\text { PFV }\end{array}$ & \\
\hline $\mathrm{CN}$ & $\begin{array}{l}\text { Hãkỹ } \\
\text { por isso } \\
\text { 'Por isso }\end{array}$ & $\begin{array}{l}f i \\
\text { 3SG.F } \\
\text { ela mell }\end{array}$ & $\begin{array}{l}t \tilde{y} \\
\text { NUC } \\
\text { horou' }\end{array}$ & $\begin{array}{l}\text { gĩnh } \\
\text { melhorar }\end{array}$ & $\begin{array}{l}\text { ke } \\
\text { fazer }\end{array}$ & $\begin{array}{l}\text { mũ. } \\
\text { PFV }\end{array}$ & \\
\hline
\end{tabular}

\section{Resultados}

Os resultados obtidos, de modo geral, demonstram, em grande parte, apoiar as nossas hipóteses. Os indices de aceitação e os tempos médios de resposta mostram que os evidenciais tendem a aceitar como complemento, sentenças que tenham conteúdo semântico convergentes às noções codificadas por essas partículas.

Da mesma forma, observa-se que as sentenças com partícula indicadora de frustrativo, aceitam melhor os complementos que trazem conteúdos semânticos compatível com o que ela codifica. Esses resultados podem ser melhor observados nas Tabelas 4 e 5 apresentados a seguir.

Tabela 4. Indice de aceitabilidade

\begin{tabular}{lcccccc}
\hline & EVCV & EVCR & ERCR & DFCF & DNCN & DNCF \\
\hline SIM & 54 & 42 & 51 & 45 & 61 & 45 \\
NÃO & 10 & 22 & 13 & 19 & 3 & 19 \\
\hline
\end{tabular}

Tabela 5. Tempos médios de resposta

\begin{tabular}{lcccccc}
\hline & EVCV & EVCR & ERCR & DFCF & DNCN & DNCF \\
\hline SIM & 1038 & 1308 & 1038 & 1395 & 1180 & 1395 \\
NÃO & 1483 & 1048 & 2685 & 1571 & 1356 & 1286 \\
\hline
\end{tabular}

Observe-se que, para a condição simétrica de evidencial visual (EVCV), a variável categórica índice de aceitação de compatibilidade, obteve 54 observações positivas, enquanto que a condição assimétrica (EVCR) 
obteve 42 observações positivas, diferença que produz resultados significativos no teste Chi quadrado: $\chi^{2}(1)=60,5, \mathrm{p}=0,0001 * * *$. Na variável contínua, tempos médios de resposta, as 54 observações positivas para a condição simétrica de evidencial visual (EVCV), foram respondidas em um tempo médio $1038 \mathrm{~ms}$, enquanto que as 42 observações positivas para a condição assimétricas (EVCR) foram respondidas em um tempo médio de $1308 \mathrm{~ms}$. Diferença que indicam distribuições significativas, em conformidade com as hipóteses entretidas. Ou seja, os resultados obtidos garantem que a preferencia pela decisão simétrica deveu-se, de fato, a variável manipulada, o evidencial visual.

O evidencial reportativo, mostra resultados parecidos do evidencial visual. Para a condição simétrica de evidencial reportativo (ERCR), a variável categórica índice de aceitação de compatibilidade, obteve 51 observações positivas, as quais foram respondidas, também, em um tempo médio de $1038 \mathrm{~ms}$, produzindo também resultados significativos no teste Chi quadrado: $\chi^{2}(1)=45,1, p=0,0001 * * *$.

Em relação ao frustrativo, observe-se que, para a condição simétrica de frustrativo (DFCF), a variável categórica índice de aceitação de compatibilidade, obteve 45 observações positivas, produzindo resultados significativos no teste Chi quadrado: $\chi^{2}(1)=21,1$, $\mathrm{p}=0,0001^{* * *}$. Na variável contínua, tempos médios de resposta, as 45 observações positivas para a condição simétrica de frustrativo (DFCF), foram respondidas em um tempo médio de $1395 \mathrm{~ms}$. No entanto, não registrase resultados muito diferente quando comparada às condições assimétricas (DNCF). Resultado que não condiz exatamente com a nossa hipótese, mas que traz pistas interessantes sobre a natureza da partícula, o conteúdo semântico que ela codifica e talvez o próprio escopo da partícula na sentença.

Um dos pontos é o fato de que nessas condições assimétricas temos a combinação de enunciado sem frustrativo (DN) seguido do complemento sem frustrativo (CF), porém, com a presença do marcador adversativo hãra 'mas' que exerce a mesma função da partícula frustrativa. Ou seja, mesmo sem a presença da partícula frustrativa o marcador adversativo consegue veicular a noção de evento frustrado pela combinação das duas sentenças 'Mĩnká tomou o remédio, mas ela não melhorou', como ilustrado pelos exemplos (7a) e (7b).
(7a)
DN Mĩnká fi tĩ vẽnhkagta kron mỹr. Mĩnká 3SG.F NUC remédio tomar VIS 'Mĩnká tomou o remédio'
(7b) CF Hãra fi pi gĩnh ke mũ. mas 3SG.F NEG melhorar fazer PFV 'Mas ela não melhorou'

Na realidade, para os falantes a combinação dessas sentenças não caracteriza uma assimetria. Isso indica também que a partícula frustrativa vã é típica de sentença simples, sem a necessidade de complemento, exatamente como é usada na oralidade Kaingang.

\section{Gráfico 3. Índices de aceitação de compatibilidade}

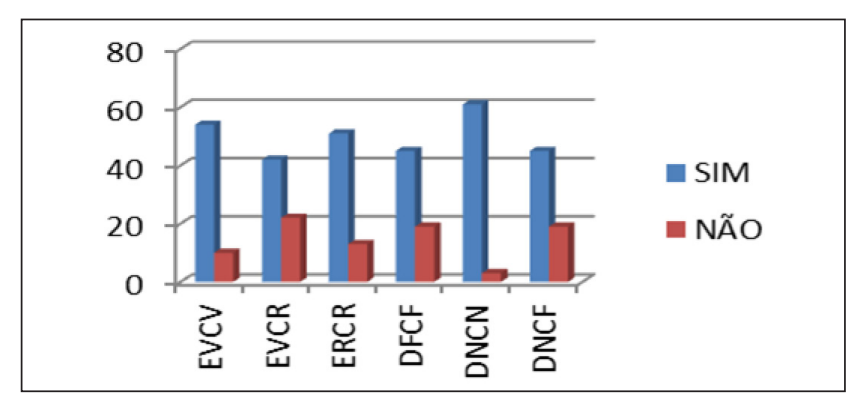

Gráfico 4. Tempos médios de resposta

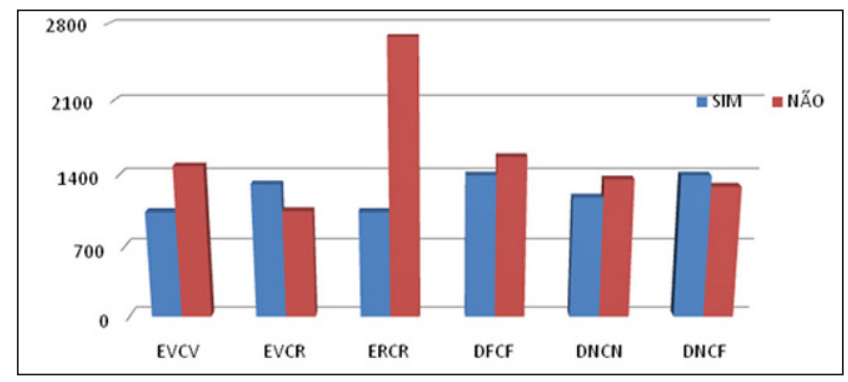

\section{Discussão}

Conforme previa a nossa hipótese, as condições simétricas de evidencial visual, bem como evidencial reportativo, tiveram maior índice de aceitabilidade, sendo elas também respondidas mais rapidamente. Esses resultados comprovam que os evidenciais tendem a aceitar como complemento, sentenças que tenham conteúdo semântico convergentes às noções codificadas por essas partículas, o que nos possibilita fazer aferições mais precisas do conteúdo semântico psicologicamente real codificado por essas partículas.

Em relação a partícula de modalidade frustrativa, além de obtermos resultados positivos que em partes confirmam nossas hipótese, registrando-se indices consideráveis de aceitabilidade das condições simétricas, bem como tempos médios de decisão, os resultados nos fornecem também, pontos importantes sobre o não estranhamento das condições assimétricas (DNCF). Nesse caso o índice de aceitabilidade dessas condições assimétricas pode ter sido provocado pela natureza da partícula frustrativa testada e a partícula de complemento hãra que são mutuamente exclusivas. Ou seja, nesse tipo de construção, a presença de apenas uma das partículas é suficiente para dar a noção de conse- 
quência frustrada. Portanto, o não estranhamento da assimetria.

\section{Considerações finais}

Neste artigo, abordamos duas questões inéditas no estudo da lingua Kaingang, a saber, a influência da prosódia sobre a categoria de tempo e a categoria de evidencialidade, ambas analisadas sob o ponto de vista da psicolinguística experimental. Com os resultados obtidos positivamente através destes estudos, consideramos que essa influencia prosódica para o Kaingang tem consequências interessantes no nível morfológico que parece ser um caso muito particular, diferentemente de outras línguas onde a prosódia atua restrita ao nível lexical, por exemplo. O que nos leva a pensar na possibilidade da emergência de um sistema tonal ou no resquício de um sistema tonal, em termos de evolução da linguagem. Um aspecto interessante da língua que sem duvida merece ser melhor investigado a fim de compreender e buscar explicações a respeito dos efeitos ou influência prosódica sobre o sistema de marcação de tempo em Kaingang.

Sobre a categoria de evidencialidade e a partícula de modalidade, o segundo experimento nos dá pistas interessantes sobre a semântica codificada por esses marcadores, permitindo avançar na investigação dessas categorias.

Finalmente, o estudo inova, reunindo questões de interesse da morfologia, da prosódia, da sintaxe, da semântica, estudadas sob o viés metodológico da psicolinguística experimental e da fonética acústica, na análise de uma língua indígena brasileira que parece ser ou apresentar um raro caso de língua acento-tonal.

\section{Referências}

AIKHENVALD, Alexandra Y. Evidentiality. New York: Oxford University Press, 2004. 452 p.
AIKHENVALD, Alexandra Y. Evidentiality in typological perspective. In: AIKHENVALD, A.Y.; DIXON, R.M. (ed.). Studies in Evidentiality. Amsterdam: John Benjamins Publishing Company, 2003. p. 1-32.

ARANTES, Pablo. Implementação em Praat de algoritmos para descrição de correlatos acústicos da prosódia da fala. In: Anais da II Jornada de Descrição do Português. Cuiabá: Sociedade Brasileira de Computação, 2011. p. 32-38.

GUSSENHOVEN, Carlos. The phonology of tone and intonation. Cambridge: Cambridge University Press, 2004.

DE HAAN, Ferdinand. Evidentiality and Mirativity. In: The Oxford Handbook of Tense and Aspect. Published in print May 2012. ISBN: 9780195381979.

HYMAN, Larry M. Word Prosody Typology. Phonology, n. 23, p. 225-257, 2006.

MORAES, João A. de. Intonation in brazilian portuguese. In: HIRST, Daniel; DI CRISTO, Albert. Intonation systems: a survey of twenty languages. Cambridge: University Press, 1998.

NASCIMENTO, Márcia. Tempo, modo, aspecto e evidencialidade em Kaingang. 2013. 140fls. Dissertação (Mestrado em Linguistica) - Universidade Federal do Rio de Janeiro, Faculdade de Letras, Rio de Janeiro, 2013.

PALMER, Frank R. Mood and Modality. Cambridge University Press. New York, 2001.

PETERSON, Tyler; SAUERLAND, Uli. Evidence from evidentials. University of British Columbia Working Papers in Linguistics. 2010.

PIERREHUMBERT, Janet B. The phonology and Phonetics of English Intonation. Tesis Doctoral. MIT, Cambridge, Massachusetts, 1980.

UGEMBE, Zeferino Maguiuane. O tom verbal em Xitshwa. Dissertação (Mestrado) - Universidade Eduardo Mondlane, Faculdade de Letras e Ciências Sociais, Maputo, 2011.

Recebido: 25 de novembro de 2015. Aprovado: 02 de junho de 2016. Contato: indiaedai@yahoo.com.br maiamarcus@gmail.com leticiarcouto@yahoo.fr 